\title{
Effect of Inclination of Rectangular Reinforced Concrete Short Columns on the Confinement
}

\author{
Eyad K. Sayhood, Bassman R. Muhammed (D), Ahmed A. Hatem* \\ Civil Engineering Department,University of Technology-Iraq, Alsina'a street, P.O BOX 10066 Baghdad, Iraq. \\ *Corresponding author Email: ahmedabbashatem@gmail.com
}

\section{H I G H L I G H T S}

- The inclination effect on the concrete column decrease confinement.

- There are certain angles that we can adopt in the design of inclined columns to avoid reducing confinement.

- The use of high strength concrete contributes greatly to avoiding the reduction of confinement in the inclined columns.

\section{A R T I C L E I N F O}

Handling editor: Wasan I. Khalil

\section{Keywords:}

Confinement

Angle of the inclination

Compressive strength

Effective depth ratio

Yield strength of steel bars

\author{
A B S T R A C T
}

\begin{abstract}
The main objective of this paper is to study the confinement of the rectangular reinforced concrete short inclined columns. This paper was based on theoretical analysis using the MATLAB program according to Universal Codes, and variables that were carefully selected to be the most influential factor. The angle of the inclination $(\alpha)$ was taken as a major variable in the paper, in addition other variables which in turn affect directly on the behavior of inclined columns such as the percentage of reinforcing steel in the concrete section of the column $(\rho)$, the compressive strength of the concrete $\left(\mathrm{f}^{\prime} \mathrm{c}\right)$, yield strength of steel bars (fy) and effective depth ratio $(\gamma)$. The results show that best ratio of reinforcing steel that improves the value of the confinement ranges from $0.4-0.6$ which leads to an increase in the confinement of $(60-100) \%$, and these rates increase with increasing $\alpha$, and the increase in $f^{\prime} c$ leads to a significant increase in the confinement, especially when HSC is used..On the other hand, decreasing fy leads to increase in confinement, and the value of the $\gamma$ had a considerable effect on the confinement that was decreased by about $11 \%$ when $\gamma$ equals 0.9 , compared with the corresponding $\gamma$ equals 0.6 .
\end{abstract}

\section{Introduction}

Transverse reinforcements in columns in the form of hoops, cross-ties, or spirals act a significant task in protection the columns, chiefly when they are exposed to intense seismic activity or side loads. They are necessary in any column whether they are roles of a moment resistant frame or the gravity technique for them to twist horizontally and supply the necessary ductility. Purpose of crosswise reinforcement is definite in design codes for beams and columns to support the following four purposes:

Avoid buckling of longitudinal reinforcing bars, withstand shear forces and to prevent shear failure, confine the concrete core to supply enough deformability (ductility), fasten together lap splices-after splitting cracks form corresponding to the splices, ties or spirals confine slipup between the joined bars. [1]

Confinement plays an important role in raising the strength of compressive strength compared with the unconfined concrete. Bearing in mind none of these purposes are influenceable till the concrete cracks or spall. The chief factor in the confinement is to enclose the concrete with hoops so that it acts like a belt, and that there are factors that plays a role in raising this confinement such as the distance between the hoops and the shape of the hoops and their number, The strain at top confined strength $\varepsilon_{\mathrm{cc}}$ is assumed as a function of the strain at top unconfined strength of concrete $\varepsilon_{\mathrm{c}}$ depending on the formula of Richart et al [2]. 


$$
\varepsilon_{c c}=\varepsilon_{c 0}\left[1+5\left(\frac{f_{c c}}{f_{c 0}}-1\right)\right]
$$

Richart et al [2] proposed the following relationship for strength applied to both spirally reinforced and hydraulically confined columns[2].

$$
f_{c c}=f_{c p}+4.1 f_{l}
$$

Popovic in [3], Utilizes the model of the equation primarily established to exemplify the stress-strain rejoinder of unconfined concrete. A constant confining pressure $f_{1}$ founded by this model. The axial stress of the confined concrete $f_{c}$ for any given strain $\varepsilon_{c}$ is correlated to the top confined strength $f_{c c}$ as shown in eq (3) and (4):

$$
\begin{aligned}
& f c=\frac{f_{c c} * x * r}{r-1+x^{r}} \\
& x=\frac{\varepsilon_{C}}{\varepsilon_{c c}}
\end{aligned}
$$

Where $\varepsilon_{c c}$ the strain at the top strength $f_{c c}$

$$
r=\frac{E_{c}}{E_{c}-E_{s e c}}
$$

Where Ec is the tangent elastic modulus of unconfined concrete and can be predestined as $5000 \sqrt{\mathrm{f}^{\prime} \mathrm{c}}(\mathrm{MPa})$. $\mathrm{E}_{\mathrm{sec}}$ is the secant modulus of confined concrete and can be predestined as $\mathrm{f}_{\mathrm{cc}} / \varepsilon_{\mathrm{cc}}$. Murray [4] developed the top confined strength $\mathrm{f}_{\mathrm{cc}}$ is a function of the unconfined strength $\mathrm{fc}$ and the constant pressure of confining $\mathrm{f}_{\mathrm{l}}$, a nonlinear correlation is suggested depending on the greatest strength surface.

$$
f_{c c}=f_{c 0}\left(-1.254+2.254 \sqrt{1+\frac{7.94 \times f_{l}}{f_{c o}}}-2 \frac{f_{l}}{f_{c 0}}\right)
$$

Kent and Park [5], Sheikh and Uzumeri [6] and Mander, Priestley, and Park [7].These researchers most famous deals with confinement, have suggested analytic models for the stress-strain curve of steel stirrups-confined concrete.

Sheikh and Khoury [8] proposed a performance-based confining reinforcement design procedure. The researchers employed curvature ductility, $\mu_{\emptyset}$ as the performance criterion in their design equations. The seismic performance of a column was classified to be in one of the following three categories: (1) highly ductile columns $\left(\mu_{\emptyset} \geq 16\right)$, (2) moderately ductile columns $\left(16>\mu_{\emptyset} \geq 8\right)$, and (3) columns displaying low levels of ductility $\left(\mu_{\emptyset}<8\right)$. The following equation was proposed and calibrated to relate the amount of lateral reinforcement in the potential plastic hinge regions of tied columns to axial load level and to curvature ductility.

$$
A_{s h}=\alpha\left[1+13\left(\frac{P}{P_{\circ}}\right)^{5}\right] \frac{\left(\mu_{\emptyset}\right)^{1.15}}{29} A_{S h, A C I}
$$

The constant $\alpha$ was used to take the arrangement of lateral and longitudinal steel into account. According to Sheikh and Khoury [8], $\alpha$ may be equal to one for tightly knit lateral reinforcement configurations in which effective lateral support to longitudinal bars is provided. In the presence of less efficient lateral reinforcement configurations and higher axial load levels, greater $\alpha$ values are recommended. They concluded that the ACI 318-95 [9],requirements for confining reinforcement may not be sufficient even in columns with efficient lateral reinforcement configurations to meet the high curvature ductility demands under moderate-to-high levels of axial loads. They recommended that at low axial load levels $(\mathrm{P} \leq 0.4 \mathrm{P})$ the code requirements may be relaxed. Bayrak and Sheikh [10] modified the equation (7) for high strength concrete columns with concrete strengths ranging from between $55 \mathrm{MPa}$ and115 $\mathrm{MPa}$.

$$
A_{s h}=\alpha\left[1+13\left(\frac{P}{P_{\circ}}\right)^{5}\right] \frac{\left(\mu_{\emptyset}\right)^{0,82}}{8.12} A_{S h, A C I}
$$

P. Paultre and F. Légeron [11] proposed new equations for the design of confinement reinforcement for conventional columns with a circular and rectangular cross section depending on performance determined in terms of curvature demand. These equations are derived from a parametric study of a very huge number of columns to get a sure level of sectional ductility and considered for the effect of concrete strength, axial load level, transverse reinforcement yield strength, and transverse confinement reinforcement especially distribution. The following parameters were chosen in the statistical study," (1) the longitudinal reinforcement ratio $\rho_{\mathrm{g}}=0.5,1.5$ and $2.5 \%$, (2) the axial load level calculated as the ratio of axial load to compressive strength of gross concrete $\mathrm{P} / \mathrm{Ag} \mathrm{f}^{\prime} \mathrm{c}=0.1,0.2,0.3,0.4,0.5$ and $0.6,(3)$ the compressive strength of concrete cylinder $\mathrm{f}^{\prime} \mathrm{c}=30,45,60,80$ and $100 \mathrm{MPa}$, with various cross section size." Simplification of these equations, while retaining the main governing factors, leads to design equations arrogate for design codes. These equations are then confirmed with a 
huge set of experimental results. Their accomplishment in the Canadian Standard for Design of Concrete Structures is described.

\section{Objectives}

The main goal of this paper is to study the effect of inclination of the concrete column on the quantity of the confinement considering variables, angle of inclination, the ratio of steel bars, concrete compressive strength, yield strength of steel bars and the value of $\gamma$.

\section{Theory and Method}

\subsection{Confinement Concept}

In vertical columns, the hoops act as ties or spiral work to increase concrete resistance and avoid buckling in the longitudinal steel bar. In beams, hoops act as a stirrup work against the shear force generated by loads, while in columns inclined, the hoops act as a composite between the two types of hoops referred to above, their function changes with the change in inclination angle of the column. The basic idea is to find an equation for this change in terms of the angle of inclination and find the critical angle through which an inclined column can be created with acceptable efficiency. Cross ties are used in columns, the load is carried by the vertical steel bars, while the ties are arranged to fix the bars in their wanted position with no developing disturbed while compacting the concrete by the vibration process, the ties are evenly spaced along with the all height of the column, from the other hand stirrups are worked to describe the transverse reinforcement arranged in beams where the essential form of load transmit through bending and shear, the stirrups are arranged to avoid cracks forming in the concrete beam due to shear, bending, and tension. The spacing of the stirrups is not constant throughout the length of the beam, they are spaced nearer close the supports and remoter apart in the middle portion. [12].

\subsection{Effecting of the inclination of RC column on the confinement}

It is not possible to impose axial load to the concrete column greater than the axial load capacity multiplied by the reduction factor, so the maximum load can be applied $(\phi \mathrm{Pn})$, and it may be less than that; depending on the level of loading, New Zealand code, representing (Ash/Sbc) as follows:

$$
\begin{aligned}
& \frac{A_{s h}}{s b_{c}}=\left[\frac{1.3-\rho_{l} m}{3.3} \frac{A_{g}}{A_{c}} \frac{f^{\prime}{ }_{c}}{f_{y t}} \frac{P}{0.85 f^{\prime}{ }^{\prime} A_{g}}\right]-0.006[14] \\
& \mathrm{e}=\frac{M_{n}}{P_{n}} \\
& \mathrm{e}=\cos \alpha l \\
& P_{n}=\frac{M_{n}}{\cos \alpha l} \\
& \text { At maximum } \phi P_{n}=P u=\frac{\phi M_{n}}{\cos \alpha l} \\
& \text { At } \alpha=90^{\circ} \longrightarrow P u=\phi P_{n} \\
& \frac{\mathrm{A}_{\mathrm{sh}}}{s b_{c}}=\left[\frac{1.3-\rho_{l} m}{3.3} \frac{A_{g}}{A_{c}} \frac{f^{\prime}{ }_{c}{ }^{\prime}}{f_{y t}} \frac{\lambda_{\alpha}\left[\frac{\phi M_{n}}{\cos \alpha l}\right]}{0.85 f^{\prime}{ }^{\prime}{ }{ }^{\prime} g}\right]-0.006 \\
& \left.\lambda_{\alpha}=\mathbf{1} \quad \text { [Proposed }\right] \\
& f_{1}=A_{s h} \frac{f_{y t}}{s b_{c}} \\
& f_{c c}=f_{c p}+4.1 f_{l}
\end{aligned}
$$

(P) which represents the applied load in terms of the load capacity of the concrete column, which is the maximum value to be carried by the column in terms inclination angle of the concrete column with the added factor $\left(\lambda_{\alpha}\right)$ represented the ratio of axially applied load to the axial load capacity of column, with keeping the minimum limit. 


\subsection{Equations of confinement}

Main factors affecting the confinement of columns given by different codes of practice are listed in Table 1.

Table 1:Equations of Main Factor, In Confinement Ash/Sbc, for Different Codes

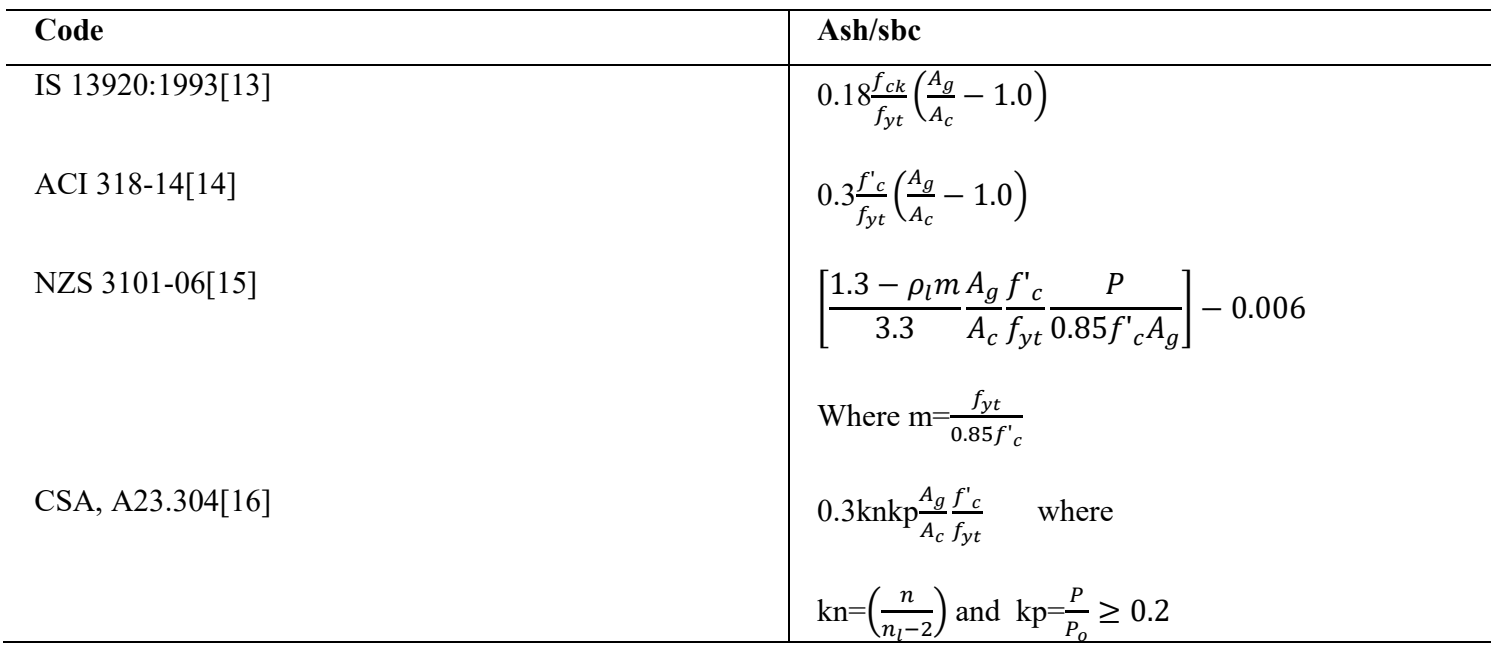

\subsection{Characteristics of the material}

The main characteristics are compressive strength in concrete, yield strength in steel and modules of elasticity of steel, a wide range of columns have been studied with concrete strength ranging from 25 to $120 \mathrm{MPa}$ confined with steel bars and having yield strength ranging from 250 to $800 \mathrm{MPa}$, the major reason for using these wide ranges for concrete strength to investigate the behavior of columns under different cases study.

\subsection{Variables of the Parametric Study}

The main variables of the investigate were angle of the inclination of the concrete column (ranging from 0 to 90 ), ratio of the reinforcing steel in the section (ranging from 0.01 to 0.09), compressive strength of the normal and high strength concrete (ranging from 20 to 120), yield strength of steel (ranging from 250 to 800 ) and gamma (ranging from 0.6to 0.9).

\section{Results and Discussion}

\subsection{Effect of inclination on the confinement}

Figure 3 Illustrated the relationship of the inclination angle and the main factor which is adopted globally in the confinement, and through the relationship below, we can clearly discover that the relationship is a clearly proportional directly, so the lower the angle of inclination less than 90 degrees (the universal vertical axis that represents the traditional column), this ratio is less, and this is due to the axial load capacity of the inclined concrete column with the inclination angle, and that most of the relationships of the international codes depend on this variable, except for the American Code. This may be the focus of criticism of the American code in this field.

\subsection{Effect of the percentage of steel bars ( $\rho)$ on the confinement}

Figure 4 describes the effect of reinforcement ratio on the confinement with different inclination angle, there is a double effect of the ratio of reinforcing steel that it is proportional to a certain extent, and then the relationship is reflected due to the problem of steel congestion. Will arise; from the other hand Figure 5 illustrate the rate of change with different reinforcement steel ratio.

\subsection{Effect compressive strength of concrete $\left(f^{\prime} c\right)$ and yield strength of steel (fy) on the confinement}

The confinement-inclination angle relationship with compressive strength of concrete and yield strength of steel for inclined column presented in Figure 6 to 9. It can be easily seen that the rise of compressive strength of concrete increased the confinement, from the other hand there is an inverse effect increased yield strength of steel decreased confinement, note that as the yield strength is raised, the amount of required confining reinforcement will be decreased, based on the hypothesis of how much strain will happen in transverse reinforcement.

\subsection{Effect of gamma $(\gamma)$ on the confinement}

Figure 11 exhibits the inclination angle of inclined column and confinement curves for the four value of $\gamma 0.6,0.7,0.8$ and 0.9 respectively, it can be noted that when the $\gamma$ decrease the $(\mathrm{Ash} / \mathrm{Sbc})$ increase because the decrease of $\gamma$ led to decline the value of $\mathrm{Ac}$ which increases the $(\mathrm{Ag} / \mathrm{Ac})$ factor in the confinement equation, but that factor has limit in international codes therefore when $\gamma$ equal 0.6 the $(\mathrm{Ash} / \mathrm{Sbc})$ drop. 


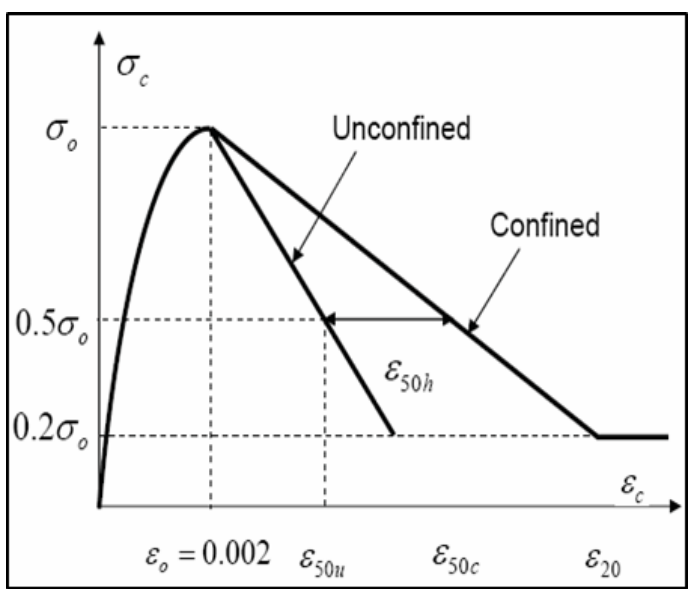

Figure 1: Columns under compression axial load Park and Kent [5]

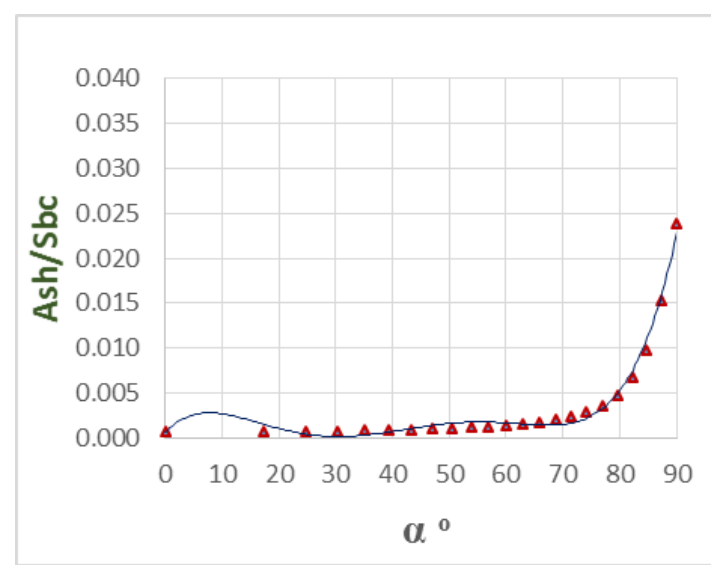

Figure 3: Illustrated the relationship between the inclination angle and the confinement

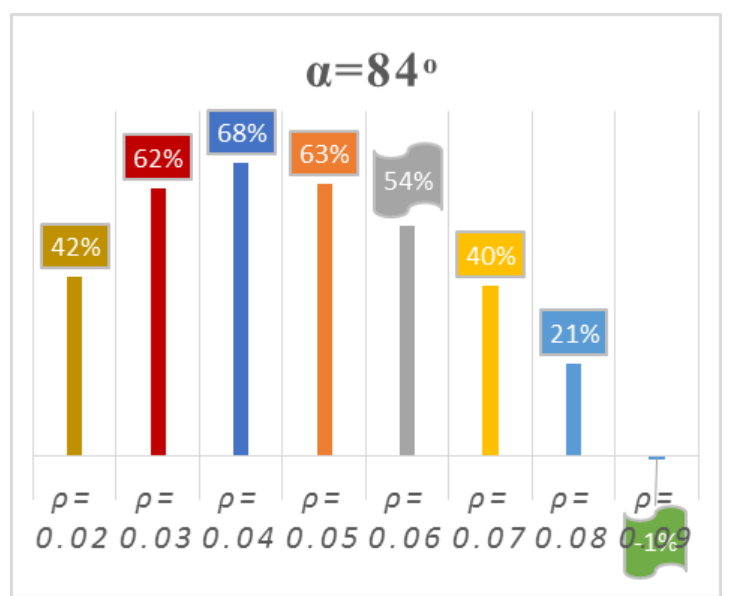

Figure 5: Illustrated the effect of $(\rho)$ on the rate of change in confinement

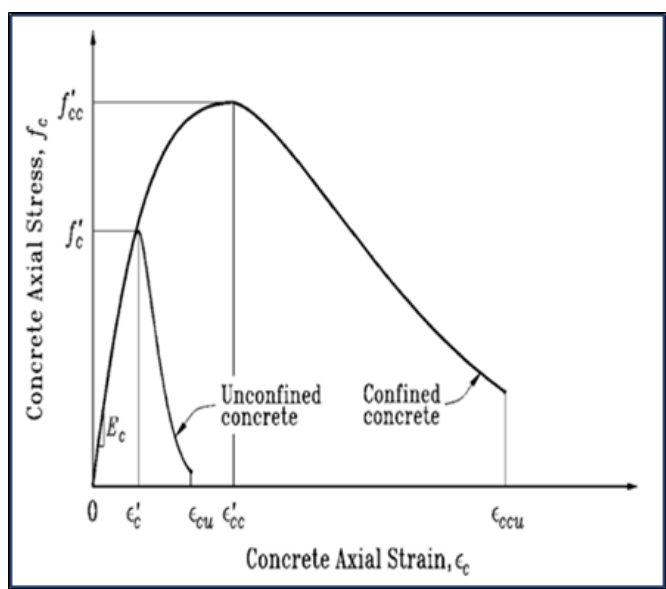

Figure 2: Described model of confinement by Mander et al. [7]

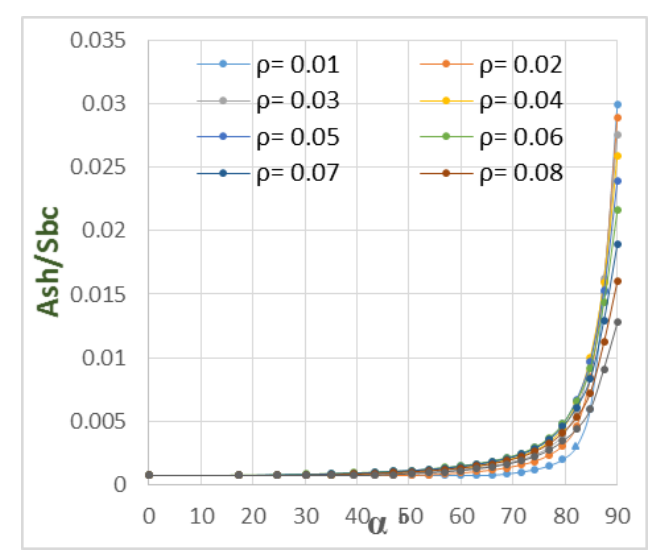

Figure 4: Illustrated the effect of $(\rho)$ on the confinement

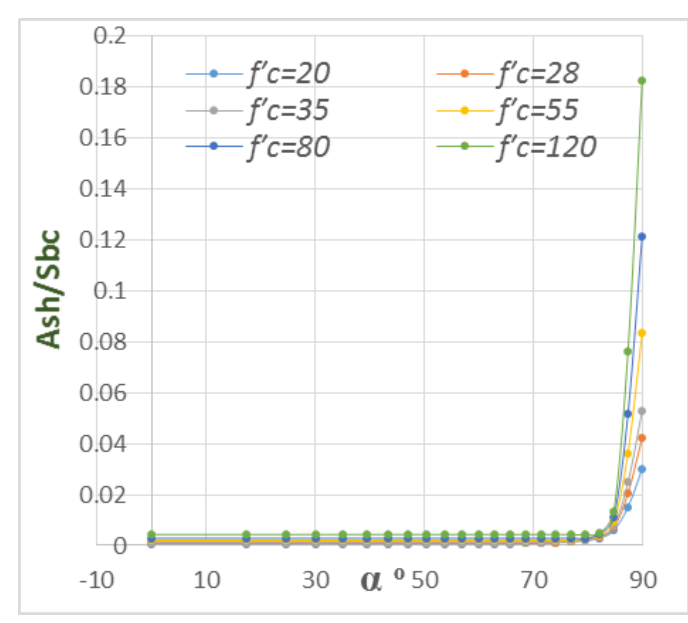

Figure 6: Illustrated the effect of $\left(f^{\prime} c\right)$ on the confinement 


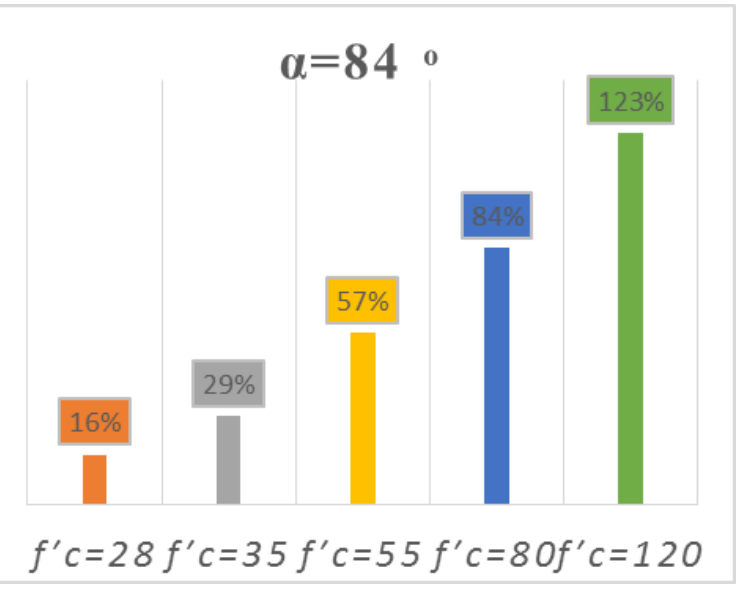

Figure 7: Illustrated the effect of $\left(f^{\prime} c\right)$ on the rate of increase axial load and moment capacity

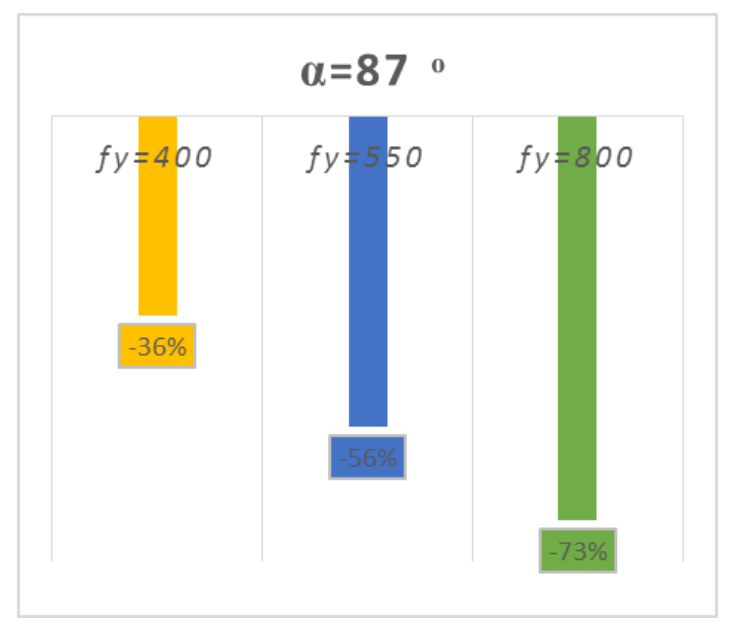

Figure 9: Illustrated the effect of $\left(f^{\prime} c\right)$ on the rate of increase axial load and moment capacity

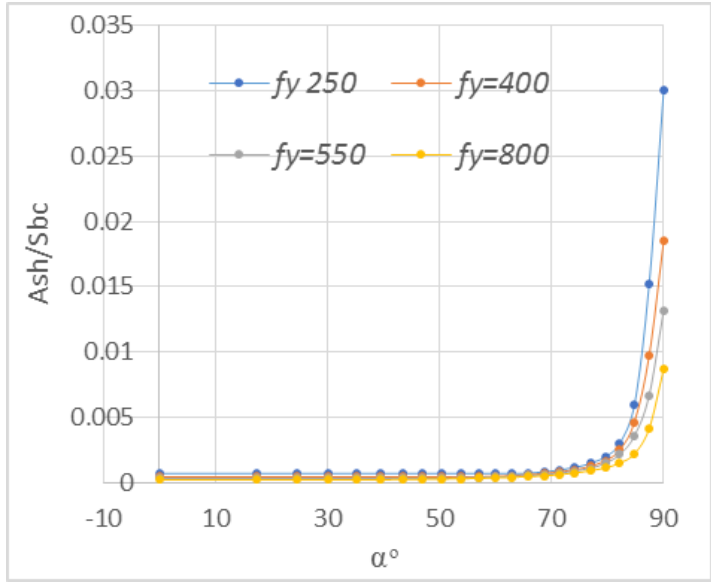

Figure 8: Illustrated the effect of (fy) on the confinement

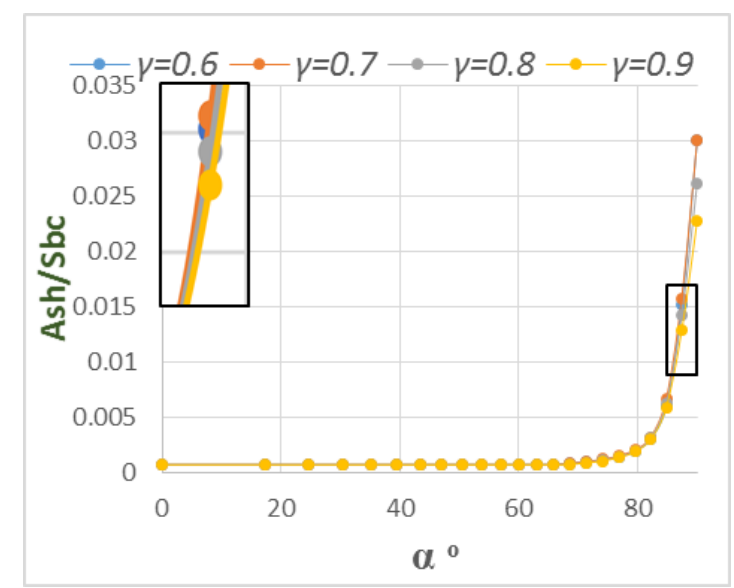

Figure 10: Illustrated the effect of $(\gamma)$ on the confinement

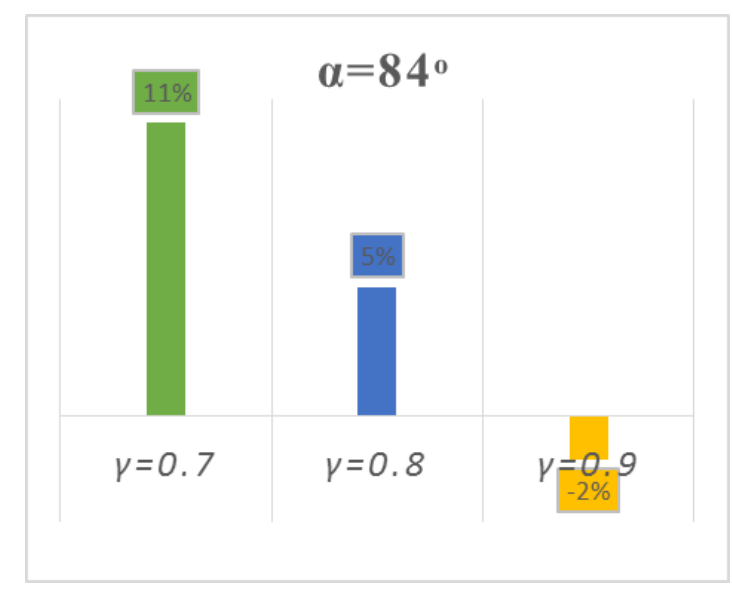

Figure 11: Illustrated the effect of $(\gamma)$ on the rate of increase axial load and moment capacity

\section{Conclusion}

The best ratio of reinforcing steel that improves the value of the confinement ranges from $0.4-0.6$ which leads to an increase in the confinement of $(60-100) \%$, and that these rates increase with increasing $\alpha$. The increase in $\mathrm{f}^{\prime} \mathrm{c}$ leads to a significant increase in the confinement, especially when used HSC, where the use of $\mathrm{f}^{\prime} \mathrm{c} 28,35 \mathrm{and} 55 \mathrm{MPa}$, leads to an increase confinement $44 \%, 75 \%$, and $175 \%$ respectively, on the other hand, decreased fy leads to increase of confinement, where using of fy 400, 550and $800 \mathrm{MPa}$, leads to a decrease in confinement $38 \%, 55 \%$, and $69 \%$ respectively. The value of the $\gamma$ had a 
considerable influence on the confinement, the confinement was decreased by about $11 \%$ when $\gamma$ equals 0.9 , compared with the corresponding $\gamma$ which to 0.6 .

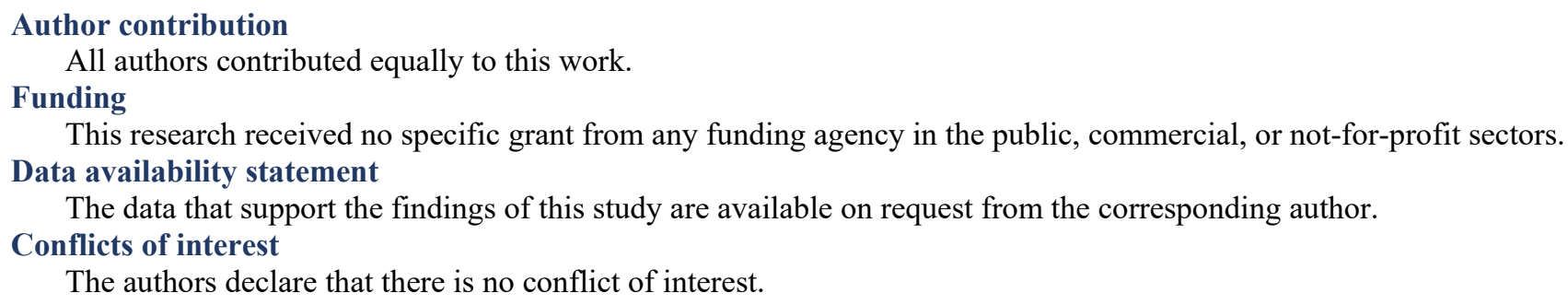

\section{References}

[1] N. Subramanian, Design of confinement reinforcement for RC columns, Indian Concr. J., 6 (2011) 1-9.

[2] F. Richart, A. Brandtzaeg and R. Brow. A study of the failure of concrete under combined compressive stresses. Engineering Experiment Station Bulletin No. 185, University of Illinois, Urbana, (1928).

[3] S. Popovics. A numerical approach to the complete stress-strain curves for concrete, Cem. Concr. Res., 5 (1973) 583-599. https://doi.org/10.1016/0008-8846(73)90096-3

[4] A. Elwi and D. Murray. A 3D Hypoelastic Concrete Constitutive Relationship. J. Eng., 105 (1979) $623-641$. https://doi.org/10.1061/JMCEA3.0002510

[5] D. Kent and R. Park, Flexural Members with Confined Concrete, Journal, Structural Division, ASCE ., 97 (1971) 19691990. https://doi.org/10.1061/JSDEAG.0002957

[6] S. Sheikh and S. Uzumeri ,Strength and ductility of tied concrete columns. (1980) 1079-112. https://doi.org/10.1061/JSDEAG.0005416

[7] J. Mander, M. Priestley and R. Park. Observed stress-strain behavior of confined concrete, J. Struct. Eng., 114 (1988)18271849.

[8] S. Sheikh and S. Khoury. Performance-Based Approach for the Design of Confining Steel in Tied Columns, ACI Struct. J., 94 (1997) 421-431.

[9] ACI Committee 318, Building Code Requirements for Structural Concrete (ACI 318M-14 (6.6.4.3)) and Commentary, American Concrete Institute, Farmington Hills, MI 48331, USA., (1995).

[10] O. Bayrak and S. Sheikh, Confinement Reinforcement Design Considerations for Ductile HSC Columns, J. Struct. Eng., ASCE., 124 (1998) 999-1010.

[11] P. Paultre and F. Légeron, Confinement Reinforcement Design for Reinforced Concrete Columns, J. Struct. Eng., 134 (2008) 738-749. http://dx.doi.org/10.1061/(ASCE)0733-9445(2008)134:5(738)

[12] S. Eyad, M. Bassman and H. Ahmed, Behavior of Reinforced Concrete Inclined Rectangular Short Columns, Master thesis, University of Technology, civil engineering department, (2019) 42-45.

[13] IS 13920:1993, Indian standards code of practice for Ductile detailing of reinforced concrete structures subjected to seismic forces, Bureau of Indian Standards, New Delhi, India.

[14] ACI Committee 318, Building Code Requirements for Structural Concrete (ACI 318M-14 (6.6.4.3)) and Commentary, American Concrete Institute, Farmington Hills, MI 48331, USA, (2014).

[15] NZS 3101:2006, Concrete Structures Standard, Part 1- The Design of Concrete Structures and Part 2 Commentary on the Design of Concrete Structures, Standards Association of New Zealand, Wellington, New Zealand, (2006) 646.

[16] CSA A23. 3-04, Design of Concrete Structures, Canadian Standards Association, Mississauga, ON, Canada, (2004) 258. 